\title{
Recent trends in managing abnormal uterine bleeding
}

\section{Shruthi Ananthula, Ushadevi Gopalan*, Sivan Kumar Kumarapillai}

\begin{abstract}
Department of Obstetrics and Gynecology, Shri Sathya Sai Medical College and Research Institute, Ammapettai,
\end{abstract} Tamil Nadu, India

Received: 17 January 2021

Accepted: 11 February 2021

\section{*Correspondence:}

Dr. Ushadevi Gopalan,

E-mail: ushag7@hotmail.com

Copyright: () the author(s), publisher and licensee Medip Academy. This is an open-access article distributed under the terms of the Creative Commons Attribution Non-Commercial License, which permits unrestricted non-commercial use, distribution, and reproduction in any medium, provided the original work is properly cited.

\begin{abstract}
Abnormal uterine bleeding is one of the most common problems among women of reproductive age. It is an important health care problem and may cause physiological as well as psychological stress impairing the quality of life. The aim of this review was to present various management options for women suffering from menorrhagia. An extensive electronic literature search was done using search engines like PubMed and Google scholar using the mesh terms/ key words like "abnormal uterine bleeding, menorrhagia, medical management, hysterectomy" to identify trials and reviews on management of abnormal uterine bleeding. Various pharmacological and surgical treatment options are available, among medical therapy Tranexamic acid being most effective. Second-generation endometrial ablation techniques are an effective and safe alternatives compared to the first-generation devices. Hysterectomy should be considered as a last resort in management of AUB as this major surgery is associated with high morbidity and mortality rates. Thus role of clinician is to counsel every women and provide full information regarding both medical as well as surgical treatment modalities available and facilitate them in making an appropriate choice.
\end{abstract}

Keywords: Abnormal uterine bleeding, Medical, Surgical, Hysterectomy

\section{INTRODUCTION}

Abnormal uterine bleeding can be defined as a variation from the normal menstrual cycle. The variation can be in regularity, frequency, duration of flow, or amount of blood loss. ${ }^{1}$

"HMB is defined as bleeding in excess of $80 \mathrm{ml}$ per menstrual cycle when measured objectively". ${ }^{2}$ The heaviest blood loss is usually on the first two days with abnormal menstruation occuring for a duration of 7 days. To estimate the menstrual blood loss objective methods can be used. However discomfort of the patient and hematological status can be taken into consideration for an appropriate management. Hallberg's alkaline hematin technique is considered as a gold standard method of estimating the blood loss. ${ }^{3}$ In this method hemoglobin is extracted by $5 \% \mathrm{NaOH}$ solution from the collected sanitary pads or tampons and the menstrual blood lost is estimated. Collection and storage of these used tampons and sanitary pads is often difficult for many women therefore a semiquantitative measurement using an alternative and simpler method known as (PBAC) pictorial blood loss assessment chart was developed by Higham. ${ }^{4}$ AUB is an important healthcare problem, causes both physiological as well as psychological stress and a common indication for hysterectomies.

Choice between medical as well as surgical management is always available for women with dysfunctional uterine bleeding to improve quality of their life and reduce blood loss. Thus the role of a clinician is to provide full details regarding all the options available and facilitate them in making an appropriate choice. The American College of Obstetricians and Gynecologists suggested that treatment of choice for each woman depends on the clinical stability, etiology, desire for future fertility, overall 
acuity, and underlying medical problems..$^{5}$ It is recommended that women presenting with abnormal uterine bleeding should be examined clinically followed by ultrasonography, or hysteroscopy preferably and blood tests (coagulation profile, platelet count). ${ }^{6}$ The main aim of this review was to furnish various treatment options available for women suffering from menorrhagia.

\section{MEDICAL TREATMENT FOR ABNORMAL UTERINE BLEEDING}

Following are the various options available for medical management of AUB -nonsteroidal anti-inflammatory drugs (NSAIDs), tranexamic acid, combined oral contraception pills, danazol, progestogens, selective estrogen receptor modulators (SERMs) and gonadotropin-releasing hormone analogues $(\mathrm{GnRH})$.

\section{Non-steroidal anti-inflammatory drugs}

NSAIDs inhibit the inflammatory mediators which help in reducing the tissue damage during menstruation. They act by inhibiting the cyclooxygenase enzymes that synthesize the prostaglandins thereby reducing the inflammation. They have reported to reduce menstrual blood loss in $10-51 \%$ of women with menorrhagia. ${ }^{7}$ NSAIDs are contraindicated in patients with bleeding disorders or abnormalities in the platelet function because of their clotting factor enhancement and platelet aggregation properties. ${ }^{8}$ They are effective in cases of AUB compared to placebo, but less effective when compared to either danazol, tranexamic acid or levonorgestrel intrauterine system. ${ }^{9}$

\section{Tranexamic acid}

It is an anti-fibrinolytic drug that reduces the blood loss in women with heavy menstrual bleeding. Tranexamic acid significantly decreases antigen levels of plasminogen activator inhibitor - type 1 and activity of endometrial tissue plasminogen activator. ${ }^{10}$ It acts by blocking the lysine binding site on plasminogen thereby preventing its interaction with the lysine residues on fibrin.

The recommend dose of this drug is $1 \mathrm{~g}$ to be taken orally 3-4 times a day during the period of heavy bleeding. It was reported that tranexamic acid at the dose of $>3 \mathrm{gm}$ daily for 5 days reduces the MBL by $34-56 \%$ and the greatest reduction in the mean MBL was reported in the first cycle of treatment. ${ }^{11}$ The side effects are headache, nausea, vomiting and gastrointestinal symptoms. As an anti-fibrinolytic agent, it also increases the risk for venous thromboembolism (VTE).

\section{Combination hormonal contraceptives}

Usage of Combined Oral contraceptives not only reduces the menstrual blood loss but also regularizes the menstrual cycle interval. ${ }^{12}$ They could either be prescribed for 21 days, followed by pill free period for 1 week to allow withdrawal bleeding or to reduce the number of withdrawal bleeding episodes, it can be given in extended cycle regimen.

A combined analysis of randomized controlled studies of this combination of estradiol valerate and dienogest showed that it significantly reduced median menstrual blood loss by $88 \%$ versus $24 \%$ with placebo. $^{13}$ Contraindications are women who are above the age of 35 years and smoke, have cardiovascular disease, hypertension, breast cancer, migraine with aura, venous thromboembolism. ${ }^{14}$

\section{Danazol}

It is a synthetic androgen exhibiting weak androgenic effects. It was found to be highly effective agent for controlling HMB compared to other medical treatments. ${ }^{15}$ Danazol inhibits the secetion of FSH and LH thereby inhibiting the development of follicle resulting in endometrial atrophy.

\section{Progestogens}

Administration of progestogens revamps the natural cycle of endometrial growth and shedding. Hickey et al, Lethaby et al in their cochrane database review have reported that progestogens given during luteal phase do not seem to be more advantageous compared with levonorgestrel-releasing intrauterine device or other hormonal medical treatments. ${ }^{16,17}$

\section{Gonadotropin-releasing hormone agonists/antagonists}

They are synthetic decapeptides that reduce secretion of (FSH) follicular stimulating hormone and (LH) luteinizing hormone from the pitutary by binding to the GnRH receptors. GnRH agonists cause endometrial atrophy and amenorrhea by suppressing the follicle development and ovarian hormone secretion. The systematic review by Lethaby et al concluded there was decrease in the menstrual blood loss and correction of preoperative anemia with use of GnRH agonists for 3-4 months before leiomyoma surgery. ${ }^{18}$ Cetin et al reported significant decrease in the menstrual blood loss and increase in hematocrit level with combination of low dose oral contraceptives and GnRH agonists (add back therapy). ${ }^{19}$

\section{Levonorgestrel-releasing intrauterine device}

Mirena was originally developed to be used as a contraceptive device, but it has been proved to be quite effective in the management of AUB. It suppresses the growth of endometrium by continuous release of levonorgestrel (progestogen) within the uterine cavity. Studies reported its maximum efficacy 1 year after insertion with a significant reduction of menstrual blood loss upto 97\%. ${ }^{17,20}$ In Hurskainen et al.'s trial it was found to be cost effective than hysterectomy. ${ }^{21}$ 


\section{Other medical options}

There are several alternative therapies for decreasing the MBL in women with HMB which include hemostatic agents, vasopressin analogues, selective estrogen receptor modulators, gestrinone, epsilon aminocaproic acid and interleukin. ${ }^{11}$ Ethamsylate is a hemostatic agent given at a dose of $500 \mathrm{mg} 4$ times daily during menstruation. Desmopressin a vasopressin analogue causes vasoconstriction and reduces MBL. Kouides et al in their study showed that desmopressin given for 2 cycles reduced the median PBAC score by $24-42 \% .^{22}$ Ormeloxifene a selective estrogen receptor modulator, prescribed at a dose of $60 \mathrm{mg}$ twice a week in Chawla et al study reported that there was rise in haemoglobin level, reduction in number of days of bleeding, reduction in endometrial thickness among women with AUB. ${ }^{23}$ In patients with poor platelet aggregation or coagulopathies Gestrinone, Epsilon aminocaproic acid and interleukin have reported to reduce $60-70 \%$ of menstrual blood loss. ${ }^{11}$

\section{Surgical treatment for abnormal uterine bleeding}

In patients with AUB who are resistant to medical line of management, alternative option of surgical management should be offered. The options include endometrial ablation techniques and hysterectomy, decision should be taken considering the patients will, age and physical condition.

\section{First-generation endometrial ablation techniques}

These techniques are based on visualizing the endometrial cavity directly through a hysteroscope.

\section{Hysteroscopic laser ablation}

Neodymium-YAG laser was the first laser method used and it destroys the endometrium with a hysteroscope. There is only 1 randomized controlled trial comparing transcervical resection with laser ablation of the endometrium and they have reported $90 \%$ satisfaction rate and $23 \%$ of the patients had amenorrhea with laser ablation. ${ }^{24}$ Inspite of its promising results, extended learning curve and high cost of the equipment remain obstacles for its application.

\section{Transcervical endometrial resection}

TCRE is effective in managing AUB. It is comparable to other ablation techniques used in terms of satisfaction rates and amenorrhea. ${ }^{25}$ The advantage of this method is treating the concomitant endometrial pathology by direct visualization of the endometrial cavity.

\section{Rollerball endometrial ablation}

Studies have reported that rollerball ablation technique had a satisfaction rate of $94 \%$, amenorrhoea rate between
29-35\%, also requires less operative time,short learning curve compared with HLA and TCRE. ${ }^{25}$ This are usually acknowledged as a gold standard technique by which new procedures are been judged..$^{25}$

\section{SECOND - GENERATION ENDOMETRIAL ABLATION TECHNIQUES}

\section{Thermal balloon endometrial ablation}

The ablation technique consists of a generator and balloon to be inserted into the endometrial cavity, the endometrim is destructed by the thermal effect caused by the hot liquid presented in the inserted balloon. Commercially available devices are Cavaterm, Thermachoice, Thermablate and Menotreat. Application of Thermachoice has reported a satisfaction rate upto $90 \%$, amenorrhoea was reported in $20 \%$ of the cases after 1 year of treatment. ${ }^{26}$ Efficacy of improved devices like Thermachoice III introduced in 2004 was evaluated and $32.6 \%$ amenorrhoea rates were reported. ${ }^{27}$ According to MAUDE and MEDLINE databases, Thermachoice is one of the safe ablation device with only $0.03 \%$ minor and major complication rate reported. ${ }^{28,29}$ In nonrandomized studies its application seems slightly improved compared to Thermachoice. ${ }^{26}$ Cavaterm cannot be used in women with length of endometrial cavity more than $10 \mathrm{~cm}$, whereas Thermachoice can be used even when the length of the endometrial cavity measures $12 \mathrm{cms}$.

\section{Endometrial ablation by hysteroscopic instillation of hot saline (hydrotherm ablator)}

This technique is also done hysteroscopically like first generation devices but is categorized under 2nd generation. Saline of $90^{\circ} \mathrm{C}$ which is externally heated is infused using the external sheath of hysteroscope into the uterine cavity, $45 \mathrm{mmHg}$ of pressure is used for infusion to prevent flow through the fallopian tubes. This hot saline causes ablation of the endometrium.

\section{Microwave endometrial ablation (MEA)}

Microwave energy of $9.2 \mathrm{GHz}$ frequency is generated in a magnetron and is applied within the endometrial cavity using a probe, after reaching a temperature of $95^{\circ} \mathrm{C}$ the ablation effect will be achieved. For this technique preparation of the endometrium pretreatment with $\mathrm{GnRH}$ analogue or danazol is necessary. In randomized trials this technique has been compared with first-generation ablative techniques like rollerball and TCRE, reported with similar results between both groups in terms of satisfaction rates and amenorrhea with minimal complications..$^{25,30}$

\section{Cryo-endometrial ablation}

In this technique ablation of the endometrium is achieved using a cooling gas at a temperature of -90 to $-100^{\circ} \mathrm{C}$. 
No difference in rate of amenorrhea was shown in only one study comparing rollerball and cryoablation. ${ }^{25}$

\section{Bipolar impedance controlled endometrial ablation technique (Novasure)}

This device consists of a single-use 3-D (dimensional) bipolar ablating probe and a radio frequency. Generally preoperative preparation of the endometrium is not required as the generator consists of a vacuum pump which suctions the debris and endometrial lining. The generator in this operates at a frequency of $500 \mathrm{KHz}$ and at $50 \Omega$ of tissue impedance it has a power cutoff limit. With this method $58 \%$ of women and $65 \%$ of women had amenorrhoea after 1 year and 3 years of postablation respectively, after 5 years there was $75 \%$ amenorrhoea rate yet this technique had an overall success upto $98 \% .^{31}$ Della et al in their study had reported a higher number of complications with Novasure compared to other ablation devices. $^{32}$

\section{Hysterectomy}

Hysterectomy is the last and permanent resort in the management of AUB especially in patients with acute life threatening hemorrhage. It is considered only when medical management has failed, patient wishes for amenorrhoea and has completed her family. It is a major surgical procedure, performed by laparotomy, laparoscopically, or vaginally requiring hospitalization for a few days to weeks and is associated with morbidity and even mortality. Complication rates due to surgical procedures were reported as $25 \%$ and $43 \%$ for vaginal hysterectomy and abdominal hysterectomy respectively in CREST study. ${ }^{33}$

\section{CONCLUSION}

Although menorrhagia is a common gynecological problem, with serious impact on social and personal life, there is always a challenge in management of this condition. Treatment options vary among medical therapy, LNG-IUD, endometrial ablation techniques and hysterectomy. In conclusion since none of the treatment options is significantly superior to another, having their own advantages and disadvantages, the treatment should be tailored for each individual patient.

Funding: No funding sources

Conflict of interest: None declared

Ethical approval: Not required

\section{REFERENCES}

1. Farrukh JB, Towriss K, McKee N. Abnormal uterine bleeding: Taking the stress out of controlling the flow. Can Fam Physician. 2015;61(8):693-7.

2. Hapangama DK, Bulmer JN. Pathophysiology of heavy menstrual bleeding. Womens Health. 2016;12(1):3-13.
3. Hallberg L, Nilsson L. Determination of menstrual blood loss. Scand J Clin Lab Invest. 1964;16:244-8.

4. Higham JM, Brien PM, Shaw RW. Assessment of menstrual blood loss using a pictorial chart. $\mathrm{Br} \mathrm{J}$ Obstet Gynaecol. 1990;97:734-9.

5. American College of Obstetricians Gynecologists. ACOG committee opinion no. 557: management of acute abnormal uterine bleeding in nonpregnant reproductive-aged women. Obstet Gynecol. 2013;121(4):891-6.

6. Dijkuizen FPHLJ, Vries LID, Mol BWJ. Comparison of transvaginal ultrasonography and saline infusion sonography for the detection of intracavitary abnormalities. Ultrasound Obstet Gynecol. 2000;15:372-6.

7. Bitzer J, Heikinheimo O, Nelson AL, Alsina J, Fraser IS. Medical management of heavy menstrual bleeding: a comprehensive review of the literature. Obstet Gynecol Surv. 2015;70(2):115-30.

8. Kadir RA, Lukes AS, Kouides PA, Fernandez H, Goudemand J. Management of excessive menstrual bleeding in women with hemostatic disorders. Fertil Steril. 2005;84(5):1352-9.

9. Lethaby A, Augood C, Duckitt K, Farquhar C. Nonsteroidal anti-inflammatory drugs for heavy menstrual bleeding. Cochrane Database Syst Rev. 2007;(4):CD000400.

10. Gleeson NC, Buggy F, Sheppard BL, Bonnar J. The effect of Tranexamic acid on measured menstrual loss and endometrial Fibrinolytic enzymes in dysfunctional uterine bleeding. Acta Obstet Gynecol Scand. 1994;73(3):274-7.

11. Bitzer J, Heikinheimo O, Nelson AL, Alsina CJ, Fraser IS. Medical management of heavy menstrual bleeding: a comprehensive review of the literature. Obstet Gynecol Surv. 2015;70(2):115-30.

12. Fraser IS, Kovacs GT. The efficacy of noncontraceptive uses for hormonal contraceptives. Med J Aust. 2003;178(12):621-3.

13. Fraser IS, Parke S, Mellinger U, Machlitt A, Serrani $\mathrm{M}$, Jensen J. Effective treatment of heavy and/or prolonged menstrual bleeding without organic cause: pooled analysis of two multinational, randomised, double-blind, placebo-controlled trials of oestradiol valerate and dienogest. Eur J Contracept Reprod Health Care. 2011;16(4):258-69.

14. Curtis KM, Tepper NK, Jatlaoui TC, Bibee BE, Horton LG, Zapata LB, et al. U.S. medical eligibility criteria for contraceptive use. MMWR Recomm Rep. 2016;65(3):1-103.

15. Beaumont HH, Augood C, Duckitt K, Lethaby A. Danazol for heavy menstrual bleeding. Cochrane Database Syst Rev. 2007;3:CD001017.

16. Hickey M, Higham JM, Fraser I. Progestogens versus oestrogens and progestogens for irregular uterine bleeding associated with anovulation. Cochrane Database Syst Rev. 2007;4:CD001895.

17. Lethaby A, Cooke I, Rees MC. Progesterone or progestogen-releasing intrauterine systems for heavy 
menstrual bleeding. Cochrane Database Syst Rev. 2005;4:CD002126.

18. Lethaby A, Vollenhoven B, Sowter M. Pre-operative GnRH analogue therapy before hysterectomy or myomectomy for uterine fibroids. Cochrane Database Syst Rev. 2001;2:CD000547.

19. Cetin NN, Karabacak O, Korucuoglu U, Karabacak N. Gonadotropin-releasing hormone analog combined with a low-dose oral contraceptive to treat heavy menstrual bleeding. Int $\mathrm{J}$ Gynaecol Obstet. 2009;104(3):236-9.

20. Mukherjee K, Jones K. The treatment of dysfunctional uterine bleeding with the Mirena IUS: a survival analysis. Gynecol Surgery. 2005;2(4):2514.

21. Hurskainen R, Teperi J, Rissanen P. Quality of life and cost-effectiveness of levonorgestrel-releasing intrauterine system versus hysterectomy for treatment of menorrhagia: a randomised trial. Lancet. 2001;357(9252):273-7.

22. Kouides PA, Byams VR, Philipp CS, Stein SF, Heit JA, Lukes AS, et al. Multisite management study of menorrhagia with abnormal laboratory haemostasis: a prospective crossover study of intranasal desmopressin and oral tranexamic acid. $\mathrm{Br} \mathrm{J}$ Haematol. 2009;145(2):212-20.

23. Chawla SK, Bucha A, Sethi A, Puar NS, Paliwal V. Use of Centchroman (Saheli) in conservative management of Menorrhagia: Our experience. Ind J Obstet Gynecol Res. 2017;4(3):220-4.

24. Bhattacharya S, Cameron IM, Parkin DE. A pragmatic randomised comparison of transcervical resection of the endometrium with endometrial laser ablation for the treatment of menorrhagia. $\mathrm{Br} \mathrm{J}$ Obstet Gynaecol. 1997;104:601-7.

25. Lethaby A, Hickey M, Garry R, Penninx J. Endometrial resection/ablation techniques for heavy menstrual bleeding. Cochrane Database Syst Rev. 2009;4:CD001501.

26. Vilos G, Edris F. Second-generation endometrial ablation technologies: the hot liquid ballons. Best Pract Res Clin Obstet Gynaecol. 2007;21(6):947-67.

27. Leal GJ, Pena A, Donovan A. Clinical evaluation of a third-generation thermal uterine balloon therapy system for menorrhagia coupled with curettage. J Min Inv Gynecol. 2010;17(1):82-90.

28. Gurtcheff SE, Sharp HT. Complications associated with global endometrial ablation: the utility of the MAUDE database. Obstet Gynecol. 2003;102:127882.

29. Weisberg M. Complications associated with global endometrial ablations: the utility of the MAUDE database. Obstet Gynecol. 2004;103:995.

30. Jameel JK, Ahmed T, Noble W, Philips K, Tised J. Microwave endometrial ablation (MEA) and bowel injury. Gynecol Surgery. 2005;2(2):131-3.

31. Marlies B. Second generation endometrial ablation treatment: Novasure. Best Pract Res Clin Obstet Gynaecol. 2005;21(6):989-94.

32. Badia DC, Nyirjesy P, Ata A. Endometrial ablation devices: review of a manufacturer and user facility device experience database. JMZIG. 2007;14:43641.

33. Lumsden MA, Twaddle S, Hawthorn R. A randomized comparison and economic evaluation of laparoscopic-assisted hysterectomy and abdominal hysterectomy. Br J Obstet Gynaecol. 2000;107:138691.

Cite this article as: Ananthula S, Gopalan U, Kumarapillai SK. Recent trends in managing abnormal uterine bleeding. Int J Reprod Contracept Obstet Gynecol 2021;10:1742-6. 